\title{
The Interaction of Lipodepsipeptide Toxins from Pseudomonas syringae pv. syringae with Biological and Model Membranes: A Comparison of Syringotoxin, Syringomycin, and Two Syringopeptins
}

\author{
Mauro Dalla Serra, ${ }^{1}$ Giulia Fagiuoli, ${ }^{1}$ Paola Nordera, ${ }^{1}$ Ivonne Bernhart, ${ }^{1}$ Claudio Della Volpe, ${ }^{2}$ \\ Domenico Di Giorgio, ${ }^{3}$ Alessandro Ballio, ${ }^{3}$ and Gianfranco Menestrina ${ }^{1}$ \\ ${ }^{1}$ CNR-ITC Centro Fisica Stati Aggregati, Via Sommarive 18, I-38050 Povo (Trento), Italy; ${ }^{2}$ Dipartimento \\ di Ingegneria dei Materiali, Università di Trento, Via Mesiano 77, I-38050 Mesiano (Trento), Italy; \\ ${ }^{3}$ Dipartimento di Scienze Biochimiche e Centro CNR di Biologia Molecolare, Roma "La Sapienza," \\ P.le Aldo Moro 5, 00185 Roma, Italy \\ Accepted 22 January 1999.
}

Pseudomonas syringae pv. syringae produces two groups of cyclic lipodepsipeptides (LDPs): the nona-peptides syringomycins, syringostatins, and syringotoxin (ST), and the more complex syringopeptins composed of either 22 or 25 amino acid residues $\left(\mathrm{SP}_{22}\right.$ and $\left.\mathrm{SP}_{25}\right)$. Both classes of peptides significantly contribute to bacterial pathogenesis and their primary target of action seems to be the plasma membrane. We studied and compared the activity of some members of these two classes of LDPs on red blood cells and on model membranes (monolayers and unilamellar vesicles). All peptides induced red blood cell hemolysis. The mechanism was apparently that of a colloid-osmotic shock caused by the formation of pores, as it could be prevented by osmoticants of adequate size. Application of the Renkin equation indicated a radius of approximately $1 \mathbf{~ n m}$ for the lesions formed by syringopeptins $\mathbf{S P}_{22} \mathbf{A}$ and $\mathbf{S P}_{25} \mathrm{~A}$, whereas those formed by syringomycin $E$ (SRE) had a variable, dose-dependent size ranging from 0.7 up to 1.7 nm. All tested LDPs displayed surface activity, forming peptide monolayers with average molecular areas of 1.2 $\mathrm{nm}^{2}$ (SRE), $1.5 \mathrm{~nm}^{2}\left(\mathrm{SP}_{22} \mathrm{~A}\right)$, and $1.3 \mathrm{~nm}^{2}\left(\mathrm{SP}_{25} \mathrm{~A}\right)$. They also partitioned into preformed lipid monolayers occupying molecular areas that ranged from 0.6 to $1.7 \mathrm{~nm}^{2}$ depending on the peptide and the lipid composition of the film. These LDPs formed channels in lipid vesicles as indicated by the release of an entrapped fluorescent dye (calcein). The extent of permeabilization was dependent on the concentration of the peptide and the composition of the lipid vesicles, with a preference for those containing a sterol. From the dose dependence of the permeabilization it was inferred that LDPs increased membrane permeability by forming oligomeric channels containing from

Corresponding author: Gianfranco Menestrina, CNR-ITC Centro di Fisica degli Stati Aggregati, via Sommarive 18, I-38050 Povo, Trento Italy; Telephone: 39461 314256; Fax: 39461 810628;

E-mail: menes@cefsa.itc.it

This paper is dedicated to the memory of Giacomino Randazzo. four to seven monomers. On average, syringopeptin oligomers were smaller than SRE and ST oligomers.

Additional keywords: calcein release, detergents, lipid bilayer.

Pseudomonas syringae pv. syringae is a phytopathogenic bacterium with a very wide range of hosts including agronomically important plant species (Synden et al. 1971; Gross and DeVay 1977). Many strains produce lipodepsipeptide (LDP) toxins that belong to two different groups: the nonapeptide group, which includes syringomycins (SRs; Segre et al. 1989; Fukuchi et al. 1990), syringostatins (Isogai et al. 1990a, 1990b; Fukuchi et al. 1992), syringotoxins (STs; Ballio et al. 1990), and pseudomycins (Ballio et al. 1994); and the group of syringopeptins (Ballio et al. 1991), with a peptide moiety of either $22\left(\mathrm{SP}_{22}\right)$ or $25\left(\mathrm{SP}_{25}\right)$ amino acid residues (see Figure 1). Both groups of metabolites might be implicated as virulence factors in the diseases induced by the bacterium (Gross and DeVay 1977; Iacobellis et al. 1992). The nonapeptides have marked antifungal activity and are potentially useful for the development of agents for the control of plant (Lam et al. 1987; Janisiewicz and Bors 1995) and human (Lam et al. 1987; Sorensen et al. 1996) diseases. As in the case of other bacterial lipopeptides (LPs) produced by Pseudomonas tolaasii, such as tolaasin (Hutchison and Johnstone 1993), or by Bacillus spp., such as iturin, surfactin, and other related antibiotics (Quentin et al. 1982; Maget-Dana et al. 1985; Maget-Dana and Ptak 1990, 1995; Sheppard et al. 1991; Yakimov et al. 1996), the primary target of their action seems to be the plasma membrane (Zhang and Takemoto 1986; Lavermicocca et al. 1997). In fact, a common mechanism, the formation of transmembrane ion channels, may underlie the action of all these molecules (Maget-Dana et al. 1985; MagetDana and Ptak 1990, 1995; Brodey et al. 1991; Hutchison et al. 1995; Feigin et al. 1996). Because some differences of action in vivo have been noted within the LDPs, e.g., syringopeptins have stronger phytotoxic and reduced antifungal activity than do SRs and STs (Iacobellis et al. 1992), we were interested in studying whether these differences could be at- 
tributed to variations in the lipid composition of the target membrane or to a different molecular action of the peptides. In particular, the involvement of ergosterol in the action of syringomycin has been demonstrated (Taguchi et al. 1994). Therefore, in this paper we have compared the mode of action of LDPs from both groups on in vitro model systems that included red blood cells (RBCs) and membranes consisting of purified lipids in the form of either monolayers or bilayers. Special attention was given to determining the role of the different sterols in this interaction.

\section{RESULTS}

RBCs.

LDPs of $P$. syringae pv. syringae are antibiotic molecules that presumably act via a relatively nonspecific attack of the plasma membrane. An example is their interaction with RBCs, which are not supposed to be a biological target (Hutchison et al. 1995). All the LDPs we tested proved to be hemolytic on both human and rabbit RBCs (Fig. 2A). The concentration required for $50 \%$ hemolysis $\left(\mathrm{C}_{50}\right)$ was slightly different among the LDPs tried, with the following order of activity: $\mathrm{SRE}>\mathrm{ST}>\mathrm{SP}_{22} \mathrm{~A} \approx \mathrm{SP}_{25} \mathrm{~A}$. The dose dependence was sigmoidal and quite steep (Fig. 2A), suggesting a cooperative behavior that could be compatible with an oligomerization mechanism. When the curves were fitted to the Hill equation the resulting Hill coefficients were 3, 3.9, 2.5, and 2.4 for SRE, ST, $\mathrm{SP}_{22} \mathrm{~A}$, and $\mathrm{SP}_{25} \mathrm{~A}$, respectively.

As with many other bacterial toxins, hemolysis could result from a colloid-osmotic shock caused by the opening of peptide-induced pores (Menestrina et al. 1994b). To test this, we investigated whether the addition of osmotic protectants in the external solution could prevent hemolysis (Fig. 2B). Indeed, sugars of increasing size reduced the rate and extent of LDPinduced hemolysis. Calculating, as we have shown earlier (Menestrina et al. 1994a), the transit time of the different sugars, and applying Renkin analysis (Renkin 1954; Ginsburg and Stein 1987), it was possible to estimate the size of the lesion. For $\mathrm{SP}_{22} \mathrm{~A}$ and $\mathrm{SP}_{25} \mathrm{~A}$ we determined a well-defined radius of $0.88 \pm 0.02 \mathrm{~nm}$ and $0.98 \pm 0.03 \mathrm{~nm}$, respectively, which was independent of LDP concentration. This indicates the forma- tion of a lesion with a fixed structure. At variance, in the case of SRE, the apparent radius changed from 0.7 to $1.7 \mathrm{~nm}$ when the concentration of toxin applied was increased from 0.6 to $3.5 \mu \mathrm{M}$. This suggests that an SRE lesion is somehow less defined in size and can grow by addition of further monomers when its concentration is increased. The formation of SRE channels of $1 \mathrm{~nm}$ radius in planar lipid bilayers was described recently (Kaulin et al. 1998). Furthermore, these channels have the tendency to form clusters that might represent the nucleus out of which larger pores are formed. In any case, the sizes that we have found should be regarded as somewhat indicative, because the assumptions necessary for the application of the Renkin equation (a perfectly cylindrical channel, a spherical diffusing particle, and no interaction between the two), are probably not entirely satisfied in the practical situation. However, at least in the case of Staphylococcus aureus $\alpha$-toxin (Krasilnikov et al. 1997), this analysis has provided an estimate of pore radius consistent with its X-ray structure (Song et al. 1996).

The ability of LDPs to affect a number of different cells, including RBCs, and to open pores in their plasma membrane, suggests they may be able to interact with the lipid matrix without the need of a receptor. We were thus prompted to investigate their interaction with simpler model membranes such as purely lipidic films.

\section{Monolayers.}

Useful information on the tendency of the LDPs to partition from the aqueous into the lipid phase can be obtained with the simplest lipid model, the monolayer. When injected into the aqueous phase, all the LDPs were able to migrate to the waterair interface, forming a monolayer and increasing the surface pressure $\pi$ (Fig. 3A). In the example shown, $\mathrm{SP}_{25} \mathrm{~A}$ was repeatedly added and changes in $\pi$ were continuously recorded. After each addition, the adsorption kinetics showed a fast and significant increase in surface pressure, followed by a slower decrease toward a steady state. This behavior has been previously observed with other, surface-active, cyclic LPs of bacterial origin (Maget-Dana and Ptak 1995). As in that case, it could indicate a rapid absorption of the LDPs to the interface in the water soluble configuration, followed by a reorganiza-

\footnotetext{
SRE: $\quad$ R-Ser-Ser $-\mathrm{Dab}^{+}-\mathrm{Dab}^{+}-\mathrm{Arg}^{+}-\mathrm{Phe}-\mathrm{Dhb}-(3-\mathrm{OH}) \mathrm{Asp}^{-}-(4-\mathrm{Cl}) \mathrm{Thr}$ L $0 \longrightarrow$

ST: $\quad$ R-Ser-Dab ${ }^{+}-G l y-H s e-O r n^{+}-T h r-D h b-(3-O H) A s p^{-}-(4-C l)$ Thr L 0

SP 25 A: R-Dhb-Pro-Val-Ala-Ala-Val-Leu-Ala-Ala-Dhb-Val-Dhb-Ala-Val-Ala-Ala-Dhb-Thr-Ser-Ala-Val $\mid$ Tyr-Dab ${ }^{+}-D a b^{+}-A I a \mid$

SP 22 A: R-Dhb-Pro-Val-VaI-Ala-Ala-Val-Val-Dhb-Ala-Val-Ala-Ala-Dhb-Thr-Ser-Ala-Dhb Tyr-Dab+ $-D a b^{+}-A 1$ a

$\mathrm{R}=\mathrm{CH}_{3}-\left(\mathrm{CH}_{2}\right)_{\mathrm{n}}-\mathrm{CH}(\mathrm{OH})-\mathrm{CH}_{2}-\mathrm{CO}$
}

Fig. 1. Primary structure of the four Pseudomonas syringae lipodepsipeptides (LDPs), identified as follows: SRE, syringomycin E; ST, syringotoxin; $\mathrm{SP}_{22} \mathrm{~A}$, syringopeptin $22 \mathrm{~A} ; \mathrm{SP}_{25} \mathrm{~A}$, syringopeptin 25A. Nonstandard amino acids are as follows: Dab, 2,4-diaminobutanoic acid; Dhb, 2,3-dehydro-2aminobutyric acid; Hse, homoserine; Orn, ornithine. $\mathrm{L}$ amino acids are in bold, D amino acids are in bold italics. The 3-hydroxy fatty acid tail has $n=8$ in SR-E, $n=10$ in ST, and $n=6$ in $\mathrm{SP}_{22} \mathrm{~A}$ and $\mathrm{SP}_{25} \mathrm{~A}$. 
tion of the molecule to a more stable and compact conformation. All the LDPs behaved similarly, albeit only $\mathrm{SP}_{25} \mathrm{~A}$ is shown. Furthermore, the same behavior was also observed in the presence of a preformed lipid monolayer. As an example, we show the adsorption of $\mathrm{SP}_{25} \mathrm{~A}$ to a monolayer composed of phosphatidylcholine (PC) and ergosterol in a 1:1 molar ratio at an initial pressure of $22 \mathrm{mN} / \mathrm{m}$ (Fig. 3B). Different LDPs and different lipid composition yielded different extent of surface pressure increase, but always a similar time course.

When the steady-state values of $\pi$ were used to calculate the LDP-induced increase $(\Delta \pi)$ versus the logarithm of LDP concentration, straight lines were obtained in both the absence and presence of a lipid monolayer (insets in Figure 3A and B, respectively). This allowed the use of the Gibbs equation to calculate the average surface area $\left(A_{\mathrm{m}}\right)$ occupied by each LDP molecule at the interface. Values of $A_{\mathrm{m}}$ for all four LDPs, either in the absence or in the presence of lipid monolayers of different composition, are listed in Table 1, together with the increments of the initial pressure at constant LDP concentration $(0.4 \mu \mathrm{M})$. Lipids used were equimolar mixtures of egg PC with one of three different sterols, all at an initial pressure of $22 \mathrm{mN} / \mathrm{m}$. In many cases we observed that LDPs occupied a smaller area in the lipid film than alone. This indicates a favorable interaction between the two molecules, since the smaller the area the smaller the Gibbs free energy of the

Fig. 2. Lipodepsipeptide (LDP)-induced lysis of human erythrocytes and the effects of osmotic protectants. A (inset), Human red blood cells (RBCs) suspended in buffer A (see text) at a concentration of $0.05 \%$ and continuously stirred were exposed to different amounts of syringopeptin $25 \mathrm{~A}\left(\mathrm{SP}_{25}\right)$. The decrease of $A_{650} \mathrm{~nm}$ indicated hemolysis. Both rate and extent of hemolysis depended on peptide concentration. A (main panel), Extent of hemolysis induced after $45 \mathrm{~min}$ by different LDPs reported as a function of their concentration. Sigmoidal shape of curves suggests cooperativity; the theoretical lines are fit to the Hill equation. The following values for $\mathrm{C}_{50}$ (concentration for half of total activity) and $h$ (Hill coefficient), were calculated: syringomycin $\mathrm{E}$ (SR), $\mathrm{C}_{50}=0.41 \mu \mathrm{M}$ and $h$ $=3$; syringotoxin $(\mathrm{ST}), \mathrm{C}_{50}=1.9 \mu \mathrm{M}$ and $h=3.9 ;$ syringopeptin $22 \mathrm{~A}$ $\left(\mathrm{SP}_{22}\right), \mathrm{C}_{50}=2.4 \mu \mathrm{M}$ and $h=2.5$; syringopeptin $25 \mathrm{~A}\left(\mathrm{SP}_{25}\right), \mathrm{C}_{50}=3.1$ $\mu \mathrm{M}$ and $h=2.4$. For the sake of clarity the trace relative to $\mathrm{SP}_{22} \mathrm{~A}$ was not reported, since it largely superimposes to that of $\mathrm{SP}_{25} \mathrm{~A}$. $\mathbf{B}$, Time course of human $\mathrm{RBC}$ hemolysis induced by $\mathrm{SP}_{25} \mathrm{~A}$ shown as in $\mathbf{A}$ (inset), except that here external solution was supplemented with 30 $\mathrm{mM}$ concentrations of the indicated sugar (glu: glucose; suc: sucrose; raf: raffinose; sta: stachiose; M7: maltoheptaose) and the peptide concentration was always $16 \mu \mathrm{M}$. Presence of the sugar retarded the kinetics of lysis to an extent that increased with size of the osmoticant. This delay was indicative of the time necessary for the sugar molecules to enter the cells through the toxin-induced lesions. B (main panel), Renkin plot (Ginsburg and Stein 1987) reporting relative diffusion rate of the osmoticant molecule vs its size. Hydrated radii used for the sugars were taken from Schultz and Solomon (1961) and Kuga (1981). Theoretical lines are best fit to the Renkin equation (Renkin 1954), yielding a functional radius of the lesion of $0.88 \pm 0.02 \mathrm{~nm}$ and $0.98 \pm 0.03 \mathrm{~nm}$ for $\mathrm{SP}_{22} \mathrm{~A}$ and $\mathrm{SP}_{25} \mathrm{~A}$, respectively. Within the experimental error given, this estimate was the same for SP concentrations ranging 8 to $20 \mu \mathrm{M}$. For the sake of clarity only the trace relative to $16 \mu \mathrm{M} \mathrm{SP}_{25} \mathrm{~A}$ was reported, since they all largely superimposed. With these two SPs, PEG (polyethylene glycol) 1000 and 2000 (with hydrated radius 1.0 and $1.4 \mathrm{~nm}$, respectively) were always fully protective, suggesting they were both impermeant. In SRE, instead, the radius estimated was variable depending on peptide concentration used. Shown is the result with a $1.5 \mu \mathrm{M}$ concentration, providing a pore radius of $1.2 \pm 0.1 \mathrm{~nm}$, but at $0.6 \mu \mathrm{M}$ peptide dose the radius was $0.7 \mathrm{~nm}$ (e.g., raffinose was virtually impermeant) whereas at $3.5 \mu \mathrm{M}$ the estimated radius was $1.7 \mathrm{~nm}$ (not shown). In the traces shown the reference sugar was glucose for $\mathrm{SP}_{25} \mathrm{~A}$ and sucrose for SRE. molecule. Values of pressure increment and molecular area with the different sterols were rather uniform among the various LDPs with just a few exceptions: ST was significantly more effective (large increment and small occupied area) with lathosterol-containing monolayers, whereas $\mathrm{SP}_{22} \mathrm{~A}$ was significantly more effective on stigmasterol-containing monolayers and less effective on those containing lathosterol (virtually ineffective). For the sake of comparison, the values reported in Table 1 should be compared with the molecular area of 0.7 $\mathrm{nm}^{2}$ occupied by a phospholipid, that of $0.55 \mathrm{~nm}^{2}$ occupied by a sterol, and that of $1.7 \mathrm{~nm}^{2}$ - estimated by a similar technique (Maget-Dana and Ptak 1995)_occupied by the lipopeptide surfactin. This last value is quite similar to those we have found with $P$. syringae LDPs.

\section{Vesicles.}

Monolayer experiments suggested that LDPs can interact with lipid membranes without a specific receptor. From
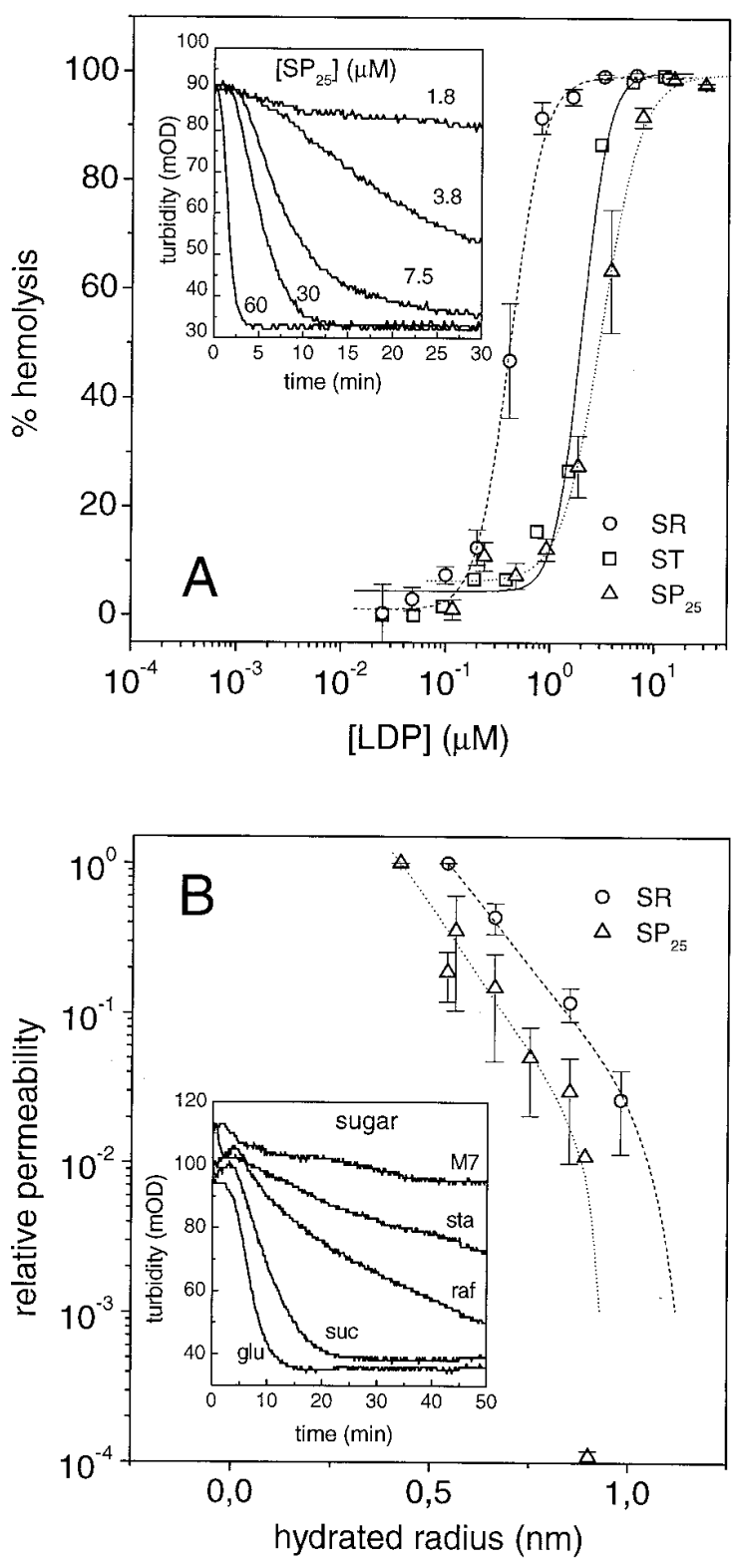

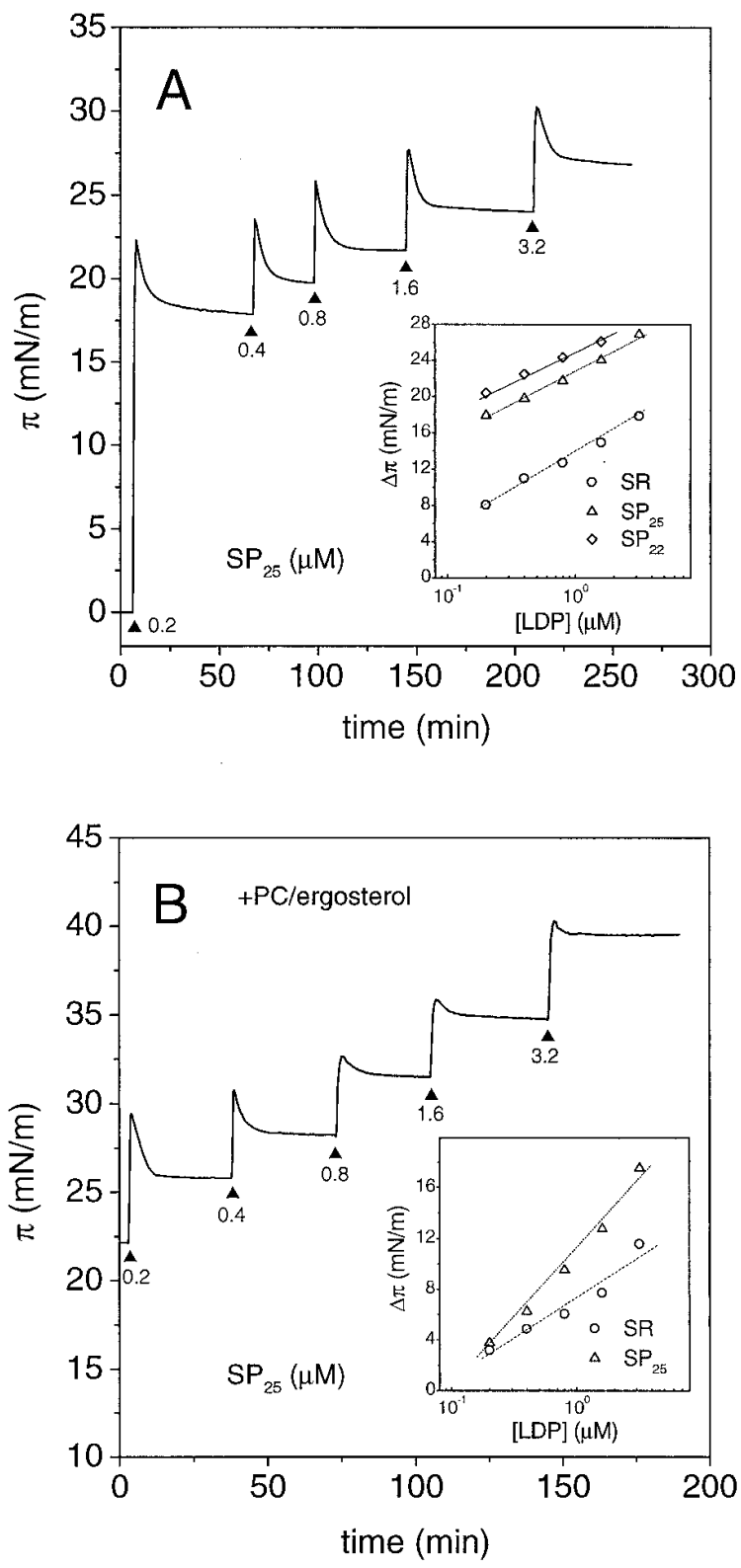

Fig. 3. Surface pressure increase induced by lipodepsipeptides (LDPs) with or without preformed lipid layers. A, Increasing doses of syringopeptin $25 \mathrm{~A}\left(\mathrm{SP}_{25}\right)$ were injected into the aqueous phase where indicated by arrowheads, and the surface pressure was continuously monitored. After each addition a fast increase in the surface pressure was followed by a slower decrease. The final concentration of $\mathrm{SP}_{25} \mathrm{~A}$ (in $\left.\mu \mathrm{M}\right)$ is indicated next to each trace. A (inset), Dose dependence of surface pressure increase at steady state $(\Delta \pi)$ was reported in a half logarithmic scale for the different LDPs. Slope of the regression lines was used to calculate the average area occupied by each molecule at the interface with the Gibbs equation (see text). These values are reported in Table 1. $\mathbf{B}$, Same as in $\mathbf{A}$ but in the presence of a lipid monolayer of initial pressure $22 \mathrm{mN} / \mathrm{m}$. The lipid used here was an equimolar mixture of phosphatidylcholine (PC) and ergosterol. Also in this case, each addition was followed by a fast increase and a slower decrease of the surface pressure. Although the extent of each increase was dependent on the kind of peptide and the lipid composition used, this transient behavior was always observed. B (inset), Dose dependence as in A, but in the presence of a PC/ergosterol monolayer of initial pressure $22 \mathrm{mN} / \mathrm{m}$. studying RBC hemolysis we had the indication that all these toxins could form pores into the cell membrane, and we were prompted to investigate whether they could also make channels in model lipid bilayers, as do many other cytolytic toxins (Menestrina et al. 1994b). Indeed, permeabilization of lipid vesicles by some $P$. syringae LDPs has been reported earlier (Camoni et al. 1995). Consistently, we found that the addition of LDPs to a solution containing large unilamellar vesicles (LUVs) loaded with calcein at a self-quenching concentration promoted the release of the dye, as indicated by an increase of the fluorescence (Fig. 4). The time course of this interaction was dependent both on the LDP type and concentration. A dose dependence of $\mathrm{SP}_{25} \mathrm{~A}$ permeabilizing activity, on vesicles of different lipid composition, is shown in Figure 5. These results could be analyzed in terms of a phenomenological model describing pore formation during peptide-vesicle interaction that was proposed by Parente et al. (1990) and later improved by Rapaport et al. (1996). This model divides the process of liposomes permeabilization into three steps: (i) peptide monomers bind and incorporate into the lipid bilayer; (ii) bound monomers reversibly aggregate to form oligomers of increasing size; and (iii) oligomers that reach a critical size form a channel through which calcein is released. By suitable simplifying assumptions, the final extent of leakage depends only on three parameters: $K_{1}$, the equilibrium constant of the incorporation process (i.e., a partition coefficient that expresses the tendency of the LDPs to insert into the lipid bilayer); $K_{2}$, the equilibrium constant for the two-dimensional aggregation of LDPs in the membrane (i.e., the tendency of inserted monomers to aggregate); and $m$, the critical size of the oligomer (i.e., the minimal number of monomers neces-

Table 1. Adsorption of the lipodepsipeptides (LDPs) to the water-air interface with or without a preformed lipid monolayer of variable composition

\begin{tabular}{llcc}
\hline Peptide $^{\mathbf{a}}$ & \multicolumn{1}{c}{ Lipid } & $\Delta \pi(\mathbf{m N} / \mathbf{m})^{\mathbf{b}}$ & $\boldsymbol{A}_{\mathbf{m}}\left(\mathbf{n m}^{\mathbf{2}}\right)^{\mathbf{c}}$ \\
\hline $\mathrm{SRE}$ & No lipid & $11.0 \pm 2.0$ & $1.21 \pm 0.07$ \\
& Ergosterol $^{\mathrm{d}}$ & $4.9 \pm 0.8$ & $1.46 \pm 0.18$ \\
& Lathosterol & $5.4 \pm 1.0$ & $1.37 \pm 0.09$ \\
$\mathrm{ST}$ & Stigmasterol & $4.5 \pm 1.3$ & $1.56 \pm 0.04$ \\
& No lipid & $\mathrm{ND}^{\mathrm{e}}$ & $\mathrm{ND}$ \\
& Ergosterol & $3.6 \pm 0.8$ & $1.08 \pm 0.05$ \\
& Lathosterol & $9.3 \pm 1.5$ & $0.59 \pm 0.05$ \\
$\mathrm{SP}_{25} \mathrm{~A}$ & Stigmasterol & $3.1 \pm 0.6$ & $1.37 \pm 0.8$ \\
& No lipid & $19.8 \pm 2.0$ & $1.28 \pm 0.04$ \\
& Ergosterol & $6.2 \pm 1.0$ & $0.82 \pm 0.05$ \\
& Lathosterol & $5.9 \pm 1.2$ & $0.87 \pm 0.11$ \\
$\mathrm{SP}_{22} \mathrm{~A}$ & Stigmasterol & $5.3 \pm 0.9$ & $1.08 \pm 0.06$ \\
& No lipid & $22.4 \pm 1.8$ & $1.49 \pm 0.04$ \\
& Ergosterol & $4.4 \pm 0.5$ & $1.58 \pm 0.18$ \\
& Lathosterol & $0.4 \pm 0.2$ & $5.19 \pm 0.39^{\mathrm{f}}$ \\
& Stigmasterol & $8.1 \pm 0.5$ & $1.71 \pm 0.07$ \\
\hline
\end{tabular}

${ }^{\mathrm{a}} \mathrm{SRE}=$ syringomycin $\mathrm{E} ; \mathrm{ST}=$ syringotoxin; $\mathrm{SP}_{22} \mathrm{~A}$ and $\mathrm{SP}_{25} \mathrm{~A}=$ syringopeptins $22 \mathrm{~A}$ or $25 \mathrm{~A}$, respectively.

${ }^{\mathrm{b}} \Delta \pi=$ increase of surface pressure observed after adding a $0.4 \mu \mathrm{M}$ concentration of the indicated LDP (experimental conditions are as in Figure 3). Values are mean \pm SD of two to three experiments.

${ }^{\mathrm{c}} A_{\mathrm{m}}$ is the average area occupied by each LDP molecule at the interface, calculated from the slope of the $\Delta \pi$ vs $\operatorname{lnC}$ plot via equation 3 (see Figure 3). Error is \pm SD.

${ }^{d}$ The sterol name indicates that a monolayer consisted of an equimolar mixture of phosphatidylcholine (PC) with that sterol, at an initial surface pressure of $\pi_{\mathrm{i}} \approx 22 \mathrm{mN} / \mathrm{m}$, was present.

e Not determined.

${ }^{\mathrm{f}}$ This large value indicates that practically no interaction occurred. 


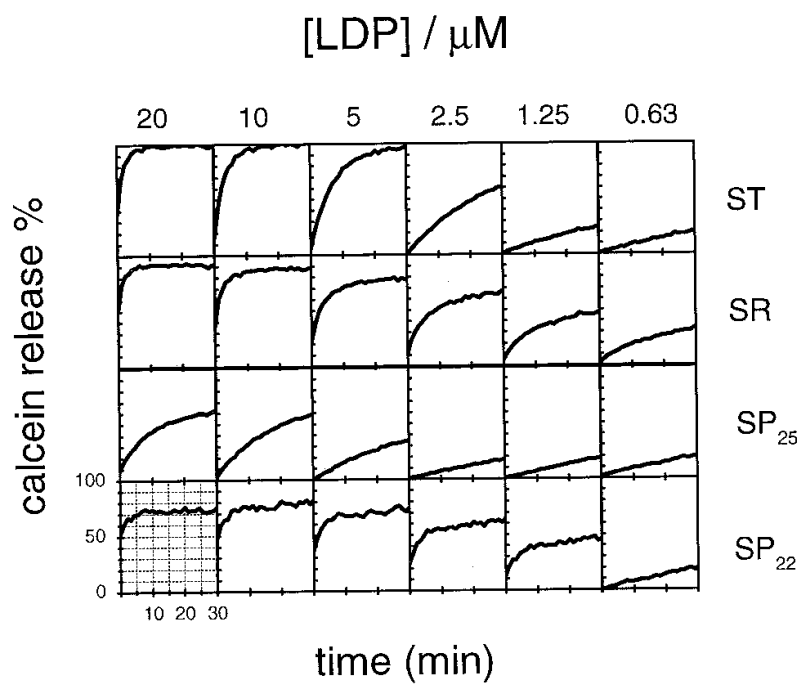

Fig. 4. Permeabilization of large unilamellar vesicles (LUVs) by different lipodepsipeptides (LDPs). The fluorescence of LUV exposed to the action of four LDPs (as indicated next to each row) was measured with a microplate reader. The LDPs were diluted in twofold steps from well to well. The amount present in each column was the same and is given on top. Lipid concentration was $6.25 \mu \mathrm{M}$ everywhere. The fluorescence intensity was converted into percent calcein released by comparing with the maximal signal obtained with Triton X-100 (see Materials and Methods). Scales are the same for each well and are indicated on the bottom left one. The whole experiment lasted $45 \mathrm{~min}$, of which only the first $30 \mathrm{~min}$ are shown.

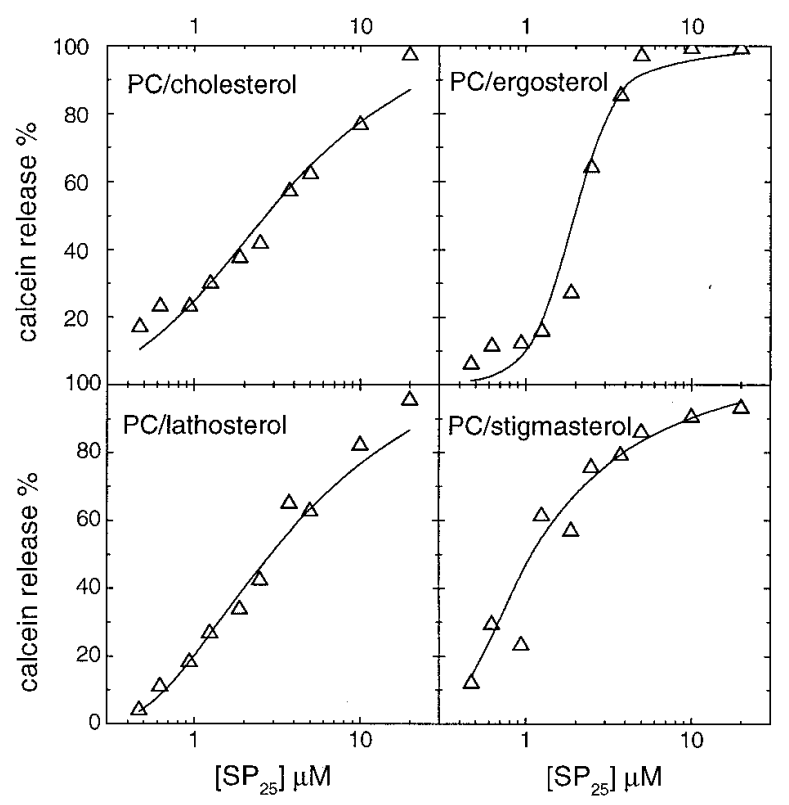

Fig. 5. Dose dependence of syringopeptin $25 \mathrm{~A}\left(\mathrm{SP}_{25}\right)$ permeabilizing activity on different vesicles. Calcein-loaded, large unilamellar vesicles (LUVs), prepared with different lipid compositions, were exposed to different doses of $\mathrm{SP}_{25} \mathrm{~A}$ and the percent calcein released after $45 \mathrm{~min}$ was determined as shown in Figure 4. Vesicles consisted of equimolar mixtures of phosphatidylcholine (PC) with one of the following sterols: cholesterol, lathosterol, ergosterol, or stigmasterol (as indicated). Lines drawn through the points are best fit according to the model described in the text (for details see also Anžlovar et al. 1998). Parameters obtained are reported in Table 3. The other three LDPs of Figure 1 gave similar results; the pertaining parameters are included in Table 3. sary to form a lesion). We have recently described in detail our implementation of this model and the derivation of the statistical error of the parameters involved (Anžlovar et al. 1998; Ferreras et al. 1998). We found that also in the present case the model was able to describe all of our results with different LDPs and different lipid compositions. The parameters that were derived are reported in Table 2 together with $\mathrm{C}_{50}$, the concentration necessary for $50 \%$ release. Looking at $\mathrm{C}_{50}$, we can notice that LUV experiments confirmed the preferences already observed with the monolayers, i.e., that of ST for lathosterol and that of $\mathrm{SP}_{22} \mathrm{~A}$ for stigmasterol (with a clear avoidance of lathosterol). Like $\mathrm{SP}_{22} \mathrm{~A}, \mathrm{SP}_{25} \mathrm{~A}$ showed a preference for stigmasterol-containing LUVs, whereas SRE was most effective on LUVs prepared with cholesterol and, to a lesser extent, ergosterol. When the kinetic parameters are examined it appears that the higher, or lower, activity is mainly due to a higher, or lower, aggregation rate $\left(K_{2}\right)$ rather than to changes in the partition constant $\left(K_{1}\right)$.

\section{Determination of LDP CMC and comparison with detergents.}

Some aspects of LDP-membrane interaction may remind of the behavior of detergents (Ruiz et al. 1988; Lasch 1995). In particular, surface activity, partitioning into lipid monolayers, permeabilization of lipid vesicles, and ability to lyse RBCs are

Table 2. Interaction of the lipodepsipeptides (LDPs) with large unilamellar vesicles (LUVs) of different composition

\begin{tabular}{llcccc}
\hline Peptide $^{\mathbf{a}}$ & \multicolumn{1}{c}{ Lipid } & $\mathbf{C}_{\mathbf{5 0}}(\boldsymbol{\mu M})^{\mathbf{b}}$ & $\boldsymbol{K}_{\mathbf{1}}\left(\mathbf{M}^{\mathbf{- 1}} \mathbf{c}^{\mathbf{c}}\right.$ & $\boldsymbol{K}_{\mathbf{2}}^{\mathbf{c}}$ & $\boldsymbol{m}^{\mathbf{c}}$ \\
\hline SRE & Cholesterol & $0.2 \pm 0.1$ & $400 \pm 50$ & $10 \pm 2$ & 5 \\
& Ergosterol & $0.8 \pm 0.3$ & $600 \pm 200$ & $0.2 \pm 0.1$ & 7 \\
& Lathosterol & $1.0 \pm 0.7$ & $400 \pm 50$ & $0.1 \pm 0.02$ & 6 \\
& Stigmasterol & $1.2 \pm 0.4$ & $400 \pm 150$ & $0.1 \pm 0.04$ & 6 \\
& PC:PE:PS & $\infty^{\mathrm{e}}$ & & & \\
$\mathrm{ST}$ & Cholesterol & $4.3 \pm 0.5$ & $400 \pm 200$ & $0.05 \pm 0.03$ & 6 \\
& Ergosterol & $4.9 \pm 0.8$ & $200 \pm 100$ & $0.05 \pm 0.02$ & 6 \\
& Lathosterol & $0.8 \pm 0.3$ & $80 \pm 20$ & $5 \pm 1$ & 6 \\
& Stigmasterol & $\approx 40^{\mathrm{f}}$ & $100 \pm 50$ & $0.010 \pm 0.005$ & 6 \\
& PC:PE:PS & $\infty^{\mathrm{e}}$ & & & \\
$\mathrm{SP}_{25} \mathrm{~A}$ & Cholesterol & $3.2 \pm 0.5$ & $200 \pm 100$ & $0.05 \pm 0.02$ & 4 \\
& Ergosterol & $1.7 \pm 0.5$ & $40 \pm 30$ & $5 \pm 1$ & 6 \\
& Lathosterol & $2.8 \pm 0.2$ & $80 \pm 20$ & $0.2 \pm 0.1$ & 5 \\
& Stigmasterol & $1.2 \pm 0.3$ & $100 \pm 20$ & $0.5 \pm 0.2$ & 5 \\
& PC:PE:PS & $0.7 \pm 0.3$ & $\mathrm{NA}$ & $\mathrm{NA}$ & $\mathrm{NA}$ \\
$\mathrm{SP}_{22} \mathrm{~A}$ & Cholesterol & $\mathrm{ND}$ & $\mathrm{ND}$ & $\mathrm{ND}$ & $\mathrm{ND}$ \\
& Ergosterol & $1.2 \pm 0.5$ & $400 \pm 100$ & $0.05 \pm 0.02$ & 4 \\
& Lathosterol & $9.1 \pm 0.5$ & $200 \pm 100$ & $0.02 \pm 0.01$ & 5 \\
& Stigmasterol & $0.4 \pm 0.2$ & $800 \pm 300$ & $0.10 \pm 0.05$ & 5 \\
& PC:PE:PS & $0.7 \pm 0.3$ & $700 \pm 400$ & $0.10 \pm 0.05$ & 6 \\
\hline
\end{tabular}

${ }^{\mathrm{a}} \mathrm{SRE}=$ syringomycin $\mathrm{E} ; \mathrm{ST}=$ syringotoxin; $\mathrm{SP}_{25} \mathrm{~A}$ and $\mathrm{SP}_{22} \mathrm{~A}=$ syringopeptins $25 \mathrm{~A}$ or $22 \mathrm{~A}$, respectively.

$\mathrm{b}$ Experimental conditions are as in Figure 5; $\mathrm{C}_{50}=\mathrm{LDP}$ concentration causing $50 \%$ release. Values are mean \pm SD of two to three experiments.

${ }^{\mathrm{c}} K_{1}$ (the equilibrium constant of incorporation), $K_{2}$ (the equilibrium constant for aggregation), and $m$ (the minimal number of monomers necessary to form a pore) have been obtained from a best fit of the model described in the text. Reported errors represent \pm SD. Error for $m$ was \pm 0.5 in all cases.

${ }^{\mathrm{d}}$ LUVs consisted of an equimolar mixture of phosphatidylcholine (PC) with the indicated sterol.

${ }^{\mathrm{e}}$ Up to the higher concentration tested $(\approx 20 \mu \mathrm{M})$ there was no indication of any release.

${ }^{\mathrm{f}}$ This value was extrapolated.

${ }^{\mathrm{g}}$ The model was not applicable in this case.

${ }^{\mathrm{h}}$ Not determined. 
all features also displayed by some detergents (Simone and Henkart 1982; Ruiz et al. 1988). Therefore, we wanted to clarify whether LDPs actually had a detergent-like mechanism of action. By contact angle measurements, we determined the critical micelle concentration (CMC) of two LDPs, the short chain $\mathrm{SRE}$ and the long chain $\mathrm{SP}_{25} \mathrm{~A}$. We found rather similar values, $1.3 \mathrm{mM}$ for $\mathrm{SRE}$ and $0.9 \mathrm{mM}$ for $\mathrm{SP}_{25} \mathrm{~A}$ (Fig. 6). This means that, being in the $\mathrm{mM}$ range, the CMCs of the LDPs are two to three orders of magnitude larger than the $\mathrm{C}_{50}$ observed for all the other effects we have described here (i.e., monolayer penetration, vesicle permeabilization, and RBC lysis).

As a control, we then investigated vesicle disruption by some detergents: polyoxyethylene (23) lauryl ether (Brij-35), sodium cholate (Na cholate), sodium dodecyl sulfate (SDS), and octylphenoxy-polyethoxy-ethanol (Triton X-100). All of them were able to release calcein from the vesicles and the dose dependence could be fitted with the same theoretical pore-formation model used for the LDPs (Fig. 7). The parameters obtained by this analysis are reported in Table 3. Several peculiar features appear. First, the ratio $\mathrm{C}_{50} / \mathrm{CMC}$ (where $\mathrm{C}_{50}$ is now the concentration for $50 \%$ vesicle permeabilization), was around 0.4 with the detergents, but two to three orders of magnitude smaller with the LDPs. Second, the parameter $m$, i.e., the size of the permeabilizing unit, was much larger with the detergents than with the LDPs (in the range 8 to 15 instead of 4 to 7). This clearly stands for a different mode of action. Interestingly, the parameter $m$ of the different detergents was found to be constantly larger than the Hill coefficient $h$, obtained by fitting the Hill equation to the same data (Table 3). A similar discrepancy was also observed in the case of LDPs when the parameter $m$, determined from vesicle permeabilization, was compared with the parameter $h$, deter-

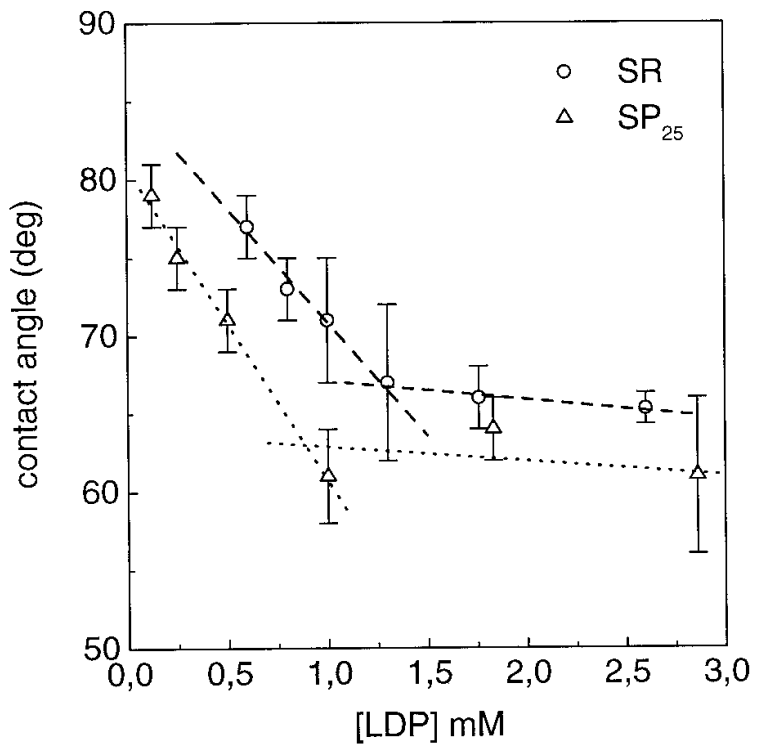

Fig. 6. Determination of the critical micellar concentration (CMC) of syringomycin $\mathrm{E}(\mathrm{SR})$ and syringopeptin $25 \mathrm{~A}\left(\mathrm{SP}_{25}\right)$. Droplets $(10 \mu \mathrm{l})$ of water containing the indicated lipodepsipeptides (LDPs) at a variable concentration were deposited on a flat polypropylene surface and the angle of contact was determined. Points are averages $\pm \mathrm{SD}$ of three to seven determinations. CMC is indicated by the peptide concentration at which the discontinuity in the slope of the angle vs concentration curve takes place (Zisman 1964). mined from RBC lysis (see Figure 1 and Table 2). In view of the results with detergents and the fact that, although common, the use of the Hill equation is questionable for permeabilization experiments (Weiss 1997), we consider the parameter $m$ to be more reliable than $h$ for estimating the size of the oligomeric lesions.

\section{DISCUSSION}

Hemolysis, vesicle permeabilization, and size of the pore.

Although RBCs are not physiological targets for LDPs, we have observed hemolytic activity with all four LDPs tried.

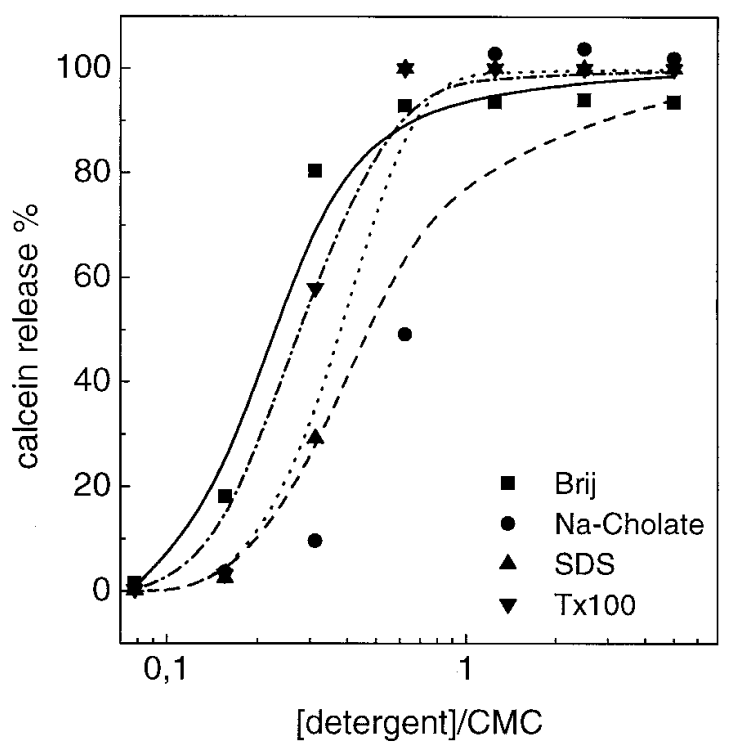

Fig. 7. Permeabilization of large unilamellar vesicles (LUVs) by ionic and non-ionic detergents. Calcein release from LUV exposed to variable amounts of detergents was determined as shown in Figure 4. Two ionic detergents (Na cholate and SDS [sodium dodecyl sulfate]) and two nonionic detergents (Brij-35 and Triton X-100) were used. Concentrations reported were normalized by dividing by the critical micellar concentration (CMC), which was 3, 1.3, 0.09, and $0.24 \mathrm{mM}$ for Na cholate, SDS, Brij-35, and Triton X-100, respectively (Helenius et al. 1979; Lichtenberg et al. 1983). Vesicles consisted of asolectin; lipid concentration was $6.25 \mu \mathrm{M}$. Lines through the points are best fit according to the phenomenological model described in the text and used also in Figure 5 (for a full description see Anžlovar et al. 1998). Parameters obtained are reported in Table 3. The same data were also fitted by the Hill equation and the resulting Hill coefficient was also reported in Table 3.

Table 3. Interaction of different detergents with large unilamellar vesicles (LUVs) of asolectin ${ }^{\mathrm{a}}$

\begin{tabular}{lccccc}
\hline Detergent & $\mathbf{C}_{\mathbf{5 0}} / \mathbf{C M C}^{\mathbf{b}}$ & $\boldsymbol{K}_{\mathbf{1}}\left(\mathbf{M}^{-\mathbf{1}}\right)^{\mathbf{b}}$ & $\boldsymbol{K}_{\mathbf{2}}^{\mathbf{b}}$ & $\boldsymbol{m}^{\mathbf{b}}$ & $\boldsymbol{h}^{\mathbf{c}}$ \\
\hline Na cholate & 0.46 & 0.2 & 3 & $11-12$ & 5.0 \\
Sodium dodecyl sulfate & 0.36 & 0.5 & $>40$ & 15 & 8.2 \\
Brij 35 & 0.22 & 6.0 & 5 & $8-9$ & 4.7 \\
Triton X-100 & 0.26 & 1.5 & $>20$ & 8 & 6.3 \\
\hline
\end{tabular}

${ }^{\text {a }}$ Experimental conditions are described in Figure 7.

${ }^{b} \mathrm{C}_{50}, K_{1}, K_{2}$, and $m$ have the same meaning as in Table 2 . They were obtained from a best fit of the data in Figure 7. CMC is the critical micellar concentration. For the sake of comparison, the ratio $\mathrm{C}_{50} / \mathrm{CMC}$ for syringomycin $\mathrm{E}$ (SRE) and syringopeptin composed of 25 amino acid residues $\left(\mathrm{SP}_{25} \mathrm{~A}\right)$ ranged, depending of the lipid composition, from 0.15 to $0.910^{-3}$ and from 0.8 to $3.510^{-3}$, respectively.

${ }^{\mathrm{c}}$ Hill coefficient obtained by a best fit of the Hill equation to the same data. 
This confirms earlier findings with SRE, ST (Hutchison et al. 1995; Sorensen et al. 1996), and $\mathrm{SP}_{22}$ (Hutchison and Gross 1997). Hemolysis was also observed with most other cyclic LPs produced by Pseudomonas spp., e.g., tolaasin (Brodey et al. 1991), or Bacillus spp., e.g., the iturin group (Quentin et al. 1982; Latoud et al. 1986). Interestingly, the $\mathrm{C}_{50} \mathrm{~s}$ were always in the range of 1 to $10 \mu \mathrm{M}$ with all these compounds. The protective effect of sugars too large to permeate through the channel was used as a means to determine pore size via the Renkin equation. We found that both syringopeptins had a radius of around $0.9 \mathrm{~nm}$ that was virtually independent of peptide concentration, indicating a stable conformation. This value is large enough to allow the passage of calcein (ionic radius $0.6 \mathrm{~nm}$ ), thus providing the basis for understanding the leakage experiments. Experiments with vesicles suggest that syringopeptin pores are formed by $5 \pm 1$ monomers. In order to surround a pore of this size they must be in an extended configuration, compatible with the molecular area of around 1 $\mathrm{nm}^{2}$ that they occupy in lipid monolayers.

With SRE instead we did not observe a single doseindependent size. The fact that raffinose was practically impermeant at low SRE concentrations suggested a minimum size of $0.66 \mathrm{~nm}$, which is consistent with a previous estimate of pore radius between 0.6 and $1 \mathrm{~nm}$ (Hutchison and Gross 1997). However, when the peptide dose was increased not only raffinose but even polyethylene glycol (PEG) of average molecular weight 2,000 (ionic radius $1.4 \mathrm{~nm}$ ) became permeant. Actually, at the highest doses tried, the Renkin plot indicated a radius of at least $1.7 \mathrm{~nm}$. This might imply that the SRE pore does not have a fixed structure but may increase in size by addition of single monomers that come into contact with the oligomer by lateral diffusion into the plane of the membrane, as for example for the alamethicin channel (Latorre and Alvarez 1981). In this regard the clustering of SRE channels of $1 \mathrm{~nm}$ radius has been observed in planar lipid bilayers (Kaulin et al. 1998). Although in these clusters every pore retains its size, it seems possible that at higher peptide concentrations some of them could coalesce to form larger structures. In this case the molecularity $m$ that we have derived from leakage experiments $(6 \pm 1$ monomers per pore) might only indicate the minimum size of the SRE pore necessary for releasing calcein. A molecularity of 6 monomers per pore for the SRE channel was also reported by others (Feigin et al. 1996). The larger pores that we have observed, e.g., those of radius $1.7 \mathrm{~nm}$ in $\mathrm{RBCs}$, are probably formed by larger oligomers. The fact that the number of molecules necessary to form a pore large enough to let calcein through is slightly larger with SRE and ST than with SPs is consistent with the fact that SPs molecules are considerably larger.

\section{Surface activity.}

The CMC values that we have determined from contact angle measurements (1.3 and $0.9 \mathrm{mM}$ for $\mathrm{SRE}$ and $\mathrm{SP}_{25} \mathrm{~A}$, respectively; Fig. 6), are similar to those reported earlier by other authors with the drop weight method (1 mM for SRE and $0.4 \mathrm{mM}$ for $\mathrm{SP}_{22}$; Hutchison et al. 1995; Hutchison and Gross 1997). However, the agreement between the two methods was much lower when the true surface tension, $\gamma$, was compared. In fact, the large contact angle measured for both LDPs at the CMC (65 to $70^{\circ}$ ) indicates that the surface tension of these solutions is considerably higher than that of polypropylene (PP), which is $\gamma_{\mathrm{s}}=31.3 \mathrm{mN} / \mathrm{m}$. They are probably near to $50 \mathrm{mN} / \mathrm{m}$, since methylene iodide, which has a $\gamma$ of $51 \mathrm{mN} / \mathrm{m}$, shows a very similar contact angle on PP. To the contrary, values determined earlier by the drop weight method were clearly smaller: $33 \mathrm{mN} / \mathrm{m}$ for SRE (Hutchison et al. 1995) and $40 \mathrm{mN} / \mathrm{m}$ for $\mathrm{SP}_{22}$ (Hutchison and Gross 1997), suggesting a stronger surface activity. The reason for this difference might be that the drop weight method, relying on the assumption that the solution perfectly wets the glass of the syringe, can suffer from some experimental artifacts if the solution contains "autophobic" cationic surfactants such as the LDPs at $\mathrm{pH}=6$. In fact, due to the favorable electrostatic interaction between their positive charge and the glass chemical functions, cationic surfactants can easily adsorb on high surface tension clean glass and prevent the solution from wetting the support (autophobic effect; see Zisman 1964). Eventually this leads to an underestimate of $\gamma$. Because this artifact is impossible in the interaction with a low surface tension solid such as PP, we think that $\gamma$ values around $50 \mathrm{mN} / \mathrm{m}$ are more realistic for LDPs, which suggests that their surface activity might have been overestimated in the past. It should also be noted that the drop weight method indicated that the long chain $\mathrm{SP}_{22}$ is less active than the short chain SRE, having a higher surface tension at CMC (Hutchison et al. 1995; Hutchison and Gross 1997), whereas we have observed the opposite both with the contact angle (Fig. 6) and with the Langmuir method (Fig. 3). This could reflect a higher autophobic effect of SRE.

\section{Role of sterols.}

ST and SRE are poorly active on lipid bilayers consisting only of phospholipids, but become active if a sterol is included. Among the sterols tested, ST showed a clear preference for lathosterol and SRE for cholesterol (both are mainly present in animal cell membranes). SRE was also very active on ergosterol (a typical component of fungi membranes). A specific interaction of SRE with ergosterol has been documented earlier (Feigin et al. 1997), and it was also found that fungi deficient in the synthesis of ergosterol are protected from SRE (Taguchi et al. 1994). Antifungal LPs of Bacillus spp. have shown a similar requirement for sterols (Quentin et al. 1982; Maget-Dana and Ptak 1990).

Syringopeptins did not show a specific requirement for sterols, being fully active also on LUV of phospholipids alone. However, as far as sterol-containing mixtures were compared, both SPs were clearly more active in the presence of stigmasterol, a peculiar component of plant cell membranes. They were less active on ergosterol (a fungal sterol) and almost inactive on cholesterol and lathosterol (animal sterols). This is consistent with their cell specificity, in fact they have been reported to be more phytotoxic but less antifungal than SR and ST (Iacobellis et al. 1992). Our finding may thus provide a basis for understanding this specificity. Furthermore, the fact that SRE and ST, but not SPs, had very low activity on vesicles composed of phospholipids alone confirms, and explains, previous experiments (Camoni et al. 1995) reporting that SPs were much more potent than SRE and ST in increasing $\mathrm{H}^{+}$permeability of sterol-free, small unilamellar vesicles (SUVs). The results that we presented here with SRE, ST, and SPs were obtained with LUVs; however, they were fully confirmed also on SUVs (data not 
shown), indicating that vesicle size is not an important parameter in this regard.

\section{MATERIALS AND METHODS}

\section{Chemicals.}

Lipids used were egg PC, egg phosphatidylethanolamine (PE), and brain phosphatidylserine (PS), all from Avanti Polar Lipids (Pelham, AL), cholesterol (Fluka, Buchs, Switzerland), lathosterol, ergosterol, stigmasterol, and asolectin (Sigma, St. Louis, MO). All lipids were more than $99 \%$ pure by thin layer chromatography. Different compositions were used as specified in the text; all binary mixtures were equimolar. Calcein, EDTA, and Sephadex were from Sigma, SDS and Brij-35 from Pierce (Rockford, IL), Triton X-100 and Na cholate from Merck (Darmstadt, Germany); Prionex (porcine hydrolyzed collagen of average mass $20 \mathrm{kDa}$ ) was from Pentapharm (Basel, Switzerland).

\section{Peptide preparation.}

SRE, ST, $\mathrm{SP}_{22} \mathrm{~A}$, and $\mathrm{SP}_{25} \mathrm{~A}$ were prepared and purified as previously described (Segre et al. 1989; Ballio et al. 1990, 1991). Their primary structure is reported in Figure 1.

\section{RBC hemolysis.}

Hemolytic activity of LDPs on human and rabbit erythrocytes was determined turbidimetrically at $650 \mathrm{~nm}$ with a 96well microplate reader as described previously (Cauci et al. 1993). Briefly: RBCs were prepared from fresh heparinized blood by washing three times in $\mathrm{NaCl} 0.85 \%$. LDPs were twofold serially diluted in a buffer containing $120 \mathrm{mM} \mathrm{NaCl}, 10$ $\mathrm{mM}$ MES (morpholineethanesulfonic acid), $1 \mathrm{mM}$ EDTA, $\mathrm{pH}$ 6.0 (called buffer A). Human RBCs, at a concentration of $0.02 \%$ in the same buffer, were then added under continuous stirring. The initial absorbance at $650 \mathrm{~nm}\left(A_{650}\right)$ was about 0.13 . Percent hemolysis was calculated as follows: $\%$ hemolysis $=100\left(A_{\mathrm{i}}-A_{\mathrm{f}}\right) /\left(A_{\mathrm{i}}-A_{\mathrm{w}}\right)$, where $A_{\mathrm{i}}$ and $A_{\mathrm{f}}$ are the absorbances at the beginning and at the end of the reaction, and $A_{\mathrm{w}}$ the value obtained after hypotonical lysis with pure water. For the pore radius estimation the assay buffer $(120 \mathrm{mM} \mathrm{NaCl}, 10$ mM HEPES [ $N$-2-hydroxyethylpiperazine- $N$-2-ethanesulfonic acid], $\mathrm{pH} 7.4$, called buffer B) was supplemented with $30 \mathrm{mM}$ concentrations of one of the following osmolites: glucose, sucrose, raffinose, maltohexaose, and maltoheptaose by Sigma, stachiose by Janssen (Geel, Belgium), PEG 200, 300, 400, 600, 900, 1,000, and 2,000, all purchased from Fluka (the numbers represent the average molecular weight). Hydrated radii of these molecules were taken from Schultz and Solomon (1961) and Kuga (1981).

\section{Calcein release assay of membrane-permeabilizing activity.}

LUVs loaded with calcein at a self-quenching concentration were used to measure membrane permeabilization as in Kayalar and Duzgunes (1986). They were prepared by extrusion through stacked polycarbonate filters with $100-\mathrm{nm}$ pores. The lipid mixtures used are detailed in the text. The assay was performed with a microplate fluorimeter (Fluostar, SLT, Groeding, Austria) as previously described (Tejuca et al. 1996). Aliquots of washed LUVs were introduced into each well to a final lipid concentration of $6.25 \mu \mathrm{M}$ in $200 \mu \mathrm{l}$ of $100 \mathrm{mM}$
$\mathrm{NaCl}, 10$ mM MES, 1 mM EDTA, pH 6.0 (buffer C). Interferometric filters at $485 \mathrm{~nm}$ in excitation and at $538 \mathrm{~nm}$ in emission were used. Maximum calcein release $\left(F_{\max }\right)$ was determined by adding $1 \mathrm{mM}$ Triton $\mathrm{X}-100$ and used as $100 \%$. The extent of permeabilization, $R \%$, was then calculated as follows: $R \%=\left(F_{\text {fin }}-F_{\text {in }}\right) /\left(F_{\text {max }}-F_{\text {in }}\right) \times 100$, where $F_{\text {in }}$ and $F_{\text {fin }}$ represent the initial and final value of fluorescence before and after protein addition, respectively. Unspecific interaction with the plastic walls of the microplate was reduced by including in the solution $0.1 \mathrm{mg}$ of Prionex per $\mathrm{ml}$. As a result, the spontaneous release of calcein was so small that it could be neglected.

\section{Monolayer.}

Monolayer experiments were performed with a computercontrolled apparatus (Minitrough from KSV, Helsinki, Finland), essentially as described previously (Nordera et al. 1997). The surface pressure of the interface was measured by the Wilhelmy method, with a $2-\mathrm{cm}$ roughened platinum plate, ensuring a zero contact angle. Solutions were prepared with tridistilled water and were stirred with a thin Teflon-coated magnetic bar. Special care was used in cleaning all wetted parts of the apparatus. Furthermore, before each experiment, surface-active impurities were removed by careful suction of the top layer. All measurements were taken at room temperature.

For the determination of their surface activity, LDPs were injected directly into the sub-phase (buffer C) through a hole in the trough wall with an Hamilton micro-syringe. In the experiments in which absorption to the lipid was studied, before the LDPs were applied, a monolayer was prepared by adding the lipid solution in small drops on top of buffer $\mathrm{C}$, until the desired initial surface pressure (normally $22 \mathrm{mN} / \mathrm{m}$ ) was reached. The lipid monolayer was always allowed to stabilize for at least half an hour before injection of the LDPs.

The average molecular area $A_{\mathrm{m}}$ occupied by each LDP at the interface was calculated from the slope of the linear part of a plot of the increase of the surface pressure $(\pi)$ versus the logarithm of the bulk LDP concentration (C) via the Gibbs equation (Seelig 1990; Nordera et al. 1997) According to Seelig (1990) the following holds: $A_{\mathrm{m}}=R T / N A \cdot(\delta \pi / \delta \operatorname{lnC})^{-1}$, where $\mathrm{N}_{\mathrm{A}}$ is Avogadro's number, $R$ the gas constant, and $T$ the absolute temperature.

\section{Contact angle measurements.}

The CMC of some LDPs ( $\mathrm{SRE}$ and $\left.\mathrm{SP}_{25} \mathrm{~A}\right)$ was determined from contact angle measurements. Droplets of $1 \mathrm{ml}$ of peptide solution in tridistilled water were deposited on a hydrophobic PP block of surface tension $\gamma_{\mathrm{s}}=31.3 \mathrm{mN} / \mathrm{m}$, as determined by the Good-van Oss acid-base method (Della Volpe et al. 1998). The static contact angle, $q$, was determined to $\pm 0.1^{\circ}$ with a homemade sessile contact angle meter with an Ealing optical bench with horizontal and vertical precision movements and a $\times 20$ microscope. Averages \pm SD of three to seven determinations were used to construct a $\theta$ versus peptide concentration graph. At the CMC the surface tension of the solution became stable around its lower value with a better wetting of the solid surface (i.e., reduced $\theta$ ). The CMC was therefore calculated as the peptide concentration at which a discontinuity occurred in the slope of the graph of $\theta$ versus surfactant concentration (see Zisman 1964). Although the original paper suggested the use of a $\cos \theta$ versus surfactant concentration graph to estimate the CMC, we observed that, due to the nonlinear response of 
the cosine function, the contact angle itself is as efficient as its cosine in the interval 60 to $90^{\circ}$ and even more precise in the 0 to $60^{\circ}$ interval.

\section{ACKNOWLEDGMENTS}

This work was financially supported by the Italian Consiglio Nazionale delle Ricerche (CNR), by the Istituto Trentino di Cultura (ITC) and by a special grant from the Provincia Autonoma di Trento (PAT, 1913/CONV/1458). M. D. S. was the recipient of a fellowship from CNR (no. 201.02.45-21.02.05); G. F., P. N., and I. B. were supported by fellowships from the Comune di Trento - Settore Sviluppo Economico.

\section{LITERATURE CITED}

Anžlovar, S., Dalla Serra, M., Dermastia, M., and Menestrina, G. 1998. Membrane permeabilizing activity of pathogenesis-related protein linusitin from flax seed. Mol. Plant-Microbe Interact. 11:610-617.

Ballio, A., Barra, D., Bossa, F., Collina, A., Grgurina, I., Marino, G., Moneti, G., Paci, M., Pucci, P., Segre, A., and Simmaco, M. 1991. Syringopeptins, new phytotoxic lipodepsipeptides of Pseudomonas syringae pv. syringae. FEBS Lett. 291:109-112.

Ballio, A., Bossa, F., Collina, A., Gallo, M., Iacobellis, N. S., Paci, M., Pucci, P., Scaloni, A., Segre, A., and Simmaco, M. 1990. Structure of syringotoxin, a bioactive metabolite of Pseudomonas syringae pv. syringae. FEBS Lett. 269:377-380.

Ballio, A., Bossa, F., Di Giorgio, D., Ferranti, P., Paci, M., Pucci, P., Scaloni, A., Segre, A., and Strobel, G. A. 1994. Novel bioactive lipodepsipeptides from Pseudomonas syringae: The pseudomycins. FEBS Lett. 355:96-100.

Brodey, C. L., Rainey, P. B., Tester, M., and Johnstone, K. 1991. Bacterial blotch disease of the cultivated mushroom is caused by an ion channel forming lipodepsipeptide toxin. Mol. Plant-Microbe Interact. 4:407-411.

Camoni, L., Di Giorgio, D., Marra, M., Aducci, P., and Ballio, A. 1995. Pseudomonas syringae pv. syringae phytotoxins reversibly inhibit the plasma membrane $\mathrm{H}^{+}$-ATPase and disrupt unilamellar liposomes. Biochem. Biophys. Res. Commun. 214:118-124.

Cauci, S., Monte, R., Ropele, M., Missero, C., Not, T., Quadrifoglio, F., and Menestrina, G. 1993. Pore-forming and hemolytic properties of the Gardnerella vaginalis cytolysin. Mol. Microbiol. 9:1143-1155.

Della Volpe, C., Deimichei, A., and Riccò, T. 1998. A multiquid approach to the surface free energy determination of flame treated surfaces of rubber-toughened polypropylene. J. Adhes. Sci. Technol. 12: $1141-1180$

Feigin, A. M., Schagina, L. V., Takemoto, J. Y., Teeter, J. H., and Brand, J. G. 1997. The effect of sterols on the sensitivity of membranes to the channel-forming antifungal antibiotic, syringomycin E. Biochim. Biophys. Acta 1324:102-110.

Feigin, A. M., Takemoto, J. Y., Wangspa, R., Teeter, J. H., and Brand, J. G. 1996. Properties of voltage-gated ion channels formed by syringomycin E in planar lipid bilayers. J. Membr. Biol. 149:41-47.

Ferreras, M., Höper, F., Dalla Serra, M., Colin, D. A., Prévost, G., and Menestrina, G. 1998. The interaction of Staphylococcus aureus bicomponent gamma hemolysins and leucocidins with cells and model membranes. Biochim. Biophys. Acta 1414:108-126.

Fukuchi, N., Isogai, A., Nakayama, J., Takayama, S., and Yamashita, S. 1992. Isolation and structural elucidation of syringostatins, phytotoxins produced by Pseudomonas syringae pv. syringae lilac isolate. J. Chem. Soc. Perkin Trans. 1:875-880.

Fukuchi, N., Isogai, A., Yamashita, S., Suyama, K., Takemoto, J. Y., and Suzuki, A. 1990. Structure of phytotoxin syringomycin produced by a sugar cane isolate of Pseudomonas syringae pv. syringae. Tetrahedron Lett. 31:1589-1592.

Ginsburg, H., and Stein, W. D. 1987. Biophysical analysis of novel transport pathways induced in red blood cell membranes. J. Membr. Biol. 96:1-10.

Gross, D. C., and DeVay, J. E. 1977. Role of syringomycin in holcus spot of maize and systemic necroses of cowpea caused by Pseudomonas syringae. Physiol. Plant Pathol. 11:1-11.

Helenius, A., McCaslin, D. R., Fries, E., and Tanford, C. 1979. Properties of detergents. Methods Enzymol. 56:734-749.
Hutchison, M. L., and Gross, D. C. 1997. Lipopeptide phytotoxins produced by Pseudomonas syringae pv. syringae: Comparison of the biosurfactant and ion channel-forming activities of syringopeptin and syringomycin. Mol. Plant-Microbe Interact. 10:347-354.

Hutchison, M. L., and Johnstone, K. 1993. Evidence for the involvement of the surface active properties of the extracellular toxin tolaasin in the manifestation of the brown blotch disease symptoms by Pseudomonas tolaasii on Agaricus bisporus. Physiol. Mol. Plant Pathol. 42: 373-384.

Hutchison, M. L., Tester, M. A., and Gross, D. C. 1995. Role of biosurfactant and ion channel-forming activities of syringomycin in transmembrane ion flux: A model for the mechanism of action in the plantpathogen interaction. Mol. Plant-Microbe Interact. 8:610-620.

Iacobellis, N. S., Lavermicocca, P., Grgurina, I., Simmaco, M., and Ballio, A. 1992. Phytotoxic properties of Pseudomonas syringae pv. syringae toxins. Physiol. Mol. Plant Pathol. 40:107-116.

Isogai, A., Fukuchi, N., Yamashita, S., Suyama, K., and Suzuki, A. 1990a. Syringostatins, novel phytotoxins produced by Pseudomonas syringae pv. syringae. Agric. Biol. Chem. 53:3117-3119.

Isogai, A., Fukuchi, N., Yamashita, S., Suyama, K., and Suzuki, A. 1990b. Structures of syringostatins A and B, novel phytotoxins produced by Pseudomonas syringae pv. syringae isolated from lilac blights. Tetrahedron Lett. 31:695-698.

Janisiewicz, W. J., and Bors, B. 1995. Development of a microbial community of bacterial and yeast antagonists to control woundinvading postharvest pathogens of fruits. Appl. Environ. Microbiol. 61:3261-3267.

Kaulin, Y. A., Schagina, L. V., Bezrukov, S. M., Malev, V. V., Feigin, A. M., Takemoto, J. Y., Teeter, J. H., and Brand, J. G. 1998. Cluster organization of ion channels formed by the antibiotic syringomycin $\mathrm{E}$ in bilayer lipid membranes. Biophys. J. 74:2918-2925

Kayalar, C., and Duzgunes, N. 1986. Membrane action of colicin E1: Detection of the release of carboxyfluorescein and calcein from liposomes. Biochim. Biophys. Acta 869:51-56.

Krasilnikov, O. V., Merzlyak, P. G., Yuldasheva, L. N., Azimova, R. K., and Nogueira, R. A. 1997. Pore-forming properties of proteolytically nicked staphylococcal alpha-toxin: The ion channel in planar lipid bilayer membranes. Med. Microbiol. Immunol. 186:53-61.

Kuga, S. 1981. Pore size distribution analysis of gel substances by size exclusion chromatography. J. Chromatogr. 206:449-461.

Lam, B. S., Strobel, G. A., Harrison, L. A., and Lam, S. T. 1987. Transposon mutagenesis and tagging of fluorescent Pseudomonas: Antimycotic production is necessary for control of dutch elm disease. Proc. Natl. Acad. Sci. USA 84:6447-6451.

Lasch, J. 1995. Interaction of detergents with lipid vesicles. Biochim. Biophys. Acta 1241:269-292.

Latorre, R., and Alvarez, O. 1981. Voltage dependent channels in planar lipid bilayer membranes. Physiol. Rev. 61:77-150.

Latoud, C., Peypoux, F., Michel, G., Genet, R., and Morgat, J. L. 1986. Interactions of antibiotics of the iturin group with human erythrocytes. Biochim. Biophys. Acta 856:526-535.

Lavermicocca, P., Iacobellis, N. S., Simmaco, M., and Graniti, A. 1997. Biological properties and spectrum of activity of Pseudomonas syringae pv. syringae toxins. Physiol. Mol. Plant Pathol. 50:129-140.

Lichtenberg, D., Robson, R. J., and Dennis, E. A. 1983. Solubilization of lipids by detergents. Structural and kinetic aspects. Biochim. Biophys. Acta 737:285-304

Maget-Dana, R., and Ptak, M. 1990. Iturin lipopeptides: Interaction of mycosubtilin with lipids in planar membranes and mixed monolayers. Biochim. Biophys. Acta 1023:34-40.

Maget-Dana, R., and Ptak, M. 1995. Interactions of surfactins with membrane models. Biophys. J. 68:1937-1943.

Maget-Dana, R., Ptak, M., Peypoux, F., and Michel, G. 1985. Poreforming properties of iturin A, a lipopeptide antibiotic. Biochim. Biophys. Acta 815:405-409.

Menestrina, G., Moser, C., Pellett, S., and Welch, R. A. 1994a. Poreformation by Escherichia coli hemolysin (HlyA) and other members of the RTX toxins family. Toxicology 87:249-267.

Menestrina, G., Schiavo, G., and Montecucco, C. 1994b. Molecular mechanism of action of bacterial protein toxins. Mol. Aspects Med. 15:79-193.

Nordera, P., Dalla Serra, M., and Menestrina, G. 1997. The adsorption of Pseudomonas aeruginosa exotoxin A to phospholipid monolayers is controlled by $\mathrm{pH}$ and surface potential. Biophys. J. 73:1468-1478. 
Parente, R. A., Nir, S., and Szoka, F. C., Jr. 1990. Mechanism of leakage of phospholipid vesicle contents induced by the peptide GALA. Biochemistry 29:8720-8728.

Quentin, M. J., Besson, F., Peypoux, F., and Michel, G. 1982. Action of peptidolipidic antibiotics of the iturin group on erythrocytes. Effect of some lipids on haemolysis. Biochim. Biophys. Acta 684:207-211.

Rapaport, D., Peled, R., Nir, S., and Shai, Y. 1996. Reversible surface aggregation in pore formation by pardaxin. Biophys. J. 70:2502-2512.

Renkin, E. M. 1954. Filtration, diffusion, and molecular sieving through porous cellulose membranes. J. Gen. Physiol. 38:225-243.

Ruiz, J., Goñi, F. M., and Alonso, A. 1988. Surfactant-induced release of liposomal contents. A survey of methods and results. Biochim. Biophys. Acta 937:127-134.

Schultz, S. G., and Solomon, A. K. 1961. Determination of the effective hydrodynamic radii of small molecules by viscometry. J. Gen. Physiol. 44:1189-1199.

Seelig, A. 1990. Substance P and antagonists. Surface activity and molecular shapes. Biochim. Biophys. Acta 1030:111-118.

Segre, A., Bachmann, R. C., Ballio, A., Bossa, F., Grgurina, I., Iacobellis, N. S., Marino, G., Pucci, P., Simmaco, M., and Takemoto, J. Y. 1989. The structure of syringomycins A1, E and G. FEBS Lett. 255: 27-31.

Sheppard, J. D., Jumarie, C., Cooper, D. G., and Laprade, R. 1991. Ionic channels induced by surfactin in planar lipid bilayer membranes. Biochim. Biophys. Acta 1064:13-23.

Simone, C. B., and Henkart, P. A. 1982. Inhibition of marker influx into complement-treated resealed erythrocytes ghosts by anti-C5. J. Immunol. 128:1168-1175.

Song, L., Hobaugh, M. R., Shustak, C., Cheley, S., Bayley, H., and Gouaux, J. E. 1996. Structure of staphylococcal alpha-hemolysin, a heptameric transmembrane pore. Science 274:1859-1866.
Sorensen, K. N., Kim, K. H., and Takemoto, J. Y. 1996. In vitro antifungal and fungicidal activities and erythrocyte toxicities of cyclic lipodepsinonapeptides produced by Pseudomonas syringae pv. syringae. Antimicrob. Agents Chemother. 40:2710-2713.

Synden, S. L., DeVay, J. E., and Backman, P. A. 1971. Properties of syringomycin, a wide spectrum antibiotic and phytotoxin produced by Pseudomonas syringae, and its role in the bacterial canker disease of peach trees. Physiol. Plant Pathol. 1:199-213.

Taguchi, N., Takano, Y., Julmanop, C., Wang, Y., Stock, S., Takemoto, J. Y., and Miyakawa, T. 1994. Identification and analysis of the Saccharomyces cerevisiae SYR1 gene reveals that ergosterol is involved in action of syringomycin. Microbiology (U.K.) 140:353-359.

Tejuca, M., Dalla Serra, M., Ferreras, M., Lanio, M. E., and Menestrina, G. 1996. The mechanism of membrane permeabilisation by sticholysin I, a cytolysin isolated from the venom of the sea anemone Stichodactyla helianthus. Biochemistry 35:14947-14957.

Weiss, J. N. 1997. The Hill equation revisited: Uses and misuses. FASEB J. 11:835-841.

Yakimov, M. M., Fredrickson, H. L., and Timmis, K. N. 1996. Effect of heterogeneity of hydrophobic moieties on surface activity of lychenysin A, a lipopeptide biosurfactant form Bacillus licheniformis BAS50. Biotechnol. Appl. Biochem. 23:13-18.

Zhang, L., and Takemoto, J. Y. 1986. Mechanism of action of Pseudomonas syringae phytotoxin, syringomycin. Interaction with the plasma membrane of wild-type and respiratory-deficient strains of Saccharomyces cerevisiae. Biochim. Biophys. Acta 861:201-204.

Zisman, W. A. 1964. Relation of equilibrium contact angle to liquid and solid constitution. Pages 1-51 in: Contact Angle, Wettability and Adhesion. R. F. Gould, ed. American Chemical Society, Washington, D.C. 